\title{
FLORENCE NIGHTINGALE: O IMPACTO DE SUAS CONTRIBUIÇÕES NO MUNDO CONTEMPORÂNEO DA ENFERMAGEM
}

Anelise Miritz Borges ${ }^{1}$, Cristiele Berthold ${ }^{2}$, Katiuscia Milano Rosales de Rodrigues $^{3}$, Sonia Maria Könzgen Meincke ${ }^{4}$, Marilu Correa Soares ${ }^{5}$, Roxana Isabel Cardozo Gonzáles ${ }^{6}$

${ }^{1}$ Mestranda do Programa de Pós-graduação de Enfermagem da Universidade Federal de Pelotas (UFPel).

${ }^{2}$ Aluna Especial do Programa de Pós-graduação de Enfermagem da Universidade Federal de Pelotas (UFPel).

${ }^{3}$ Mestranda do Programa de Pós-graduação de Enfermagem da Universidade Federal de Pelotas (UFPel).

${ }^{4}$ Doutora. Docente da Faculdade de Enfermagem da Universidade Federal de Pelotas (UFPel).

${ }^{5}$ Doutora. Docente da Faculdade de Enfermagem da Universidade Federal de Pelotas (UFPel).

${ }^{6}$ Doutora. Docente da Universidade Federal de Pelotas (UFPel).

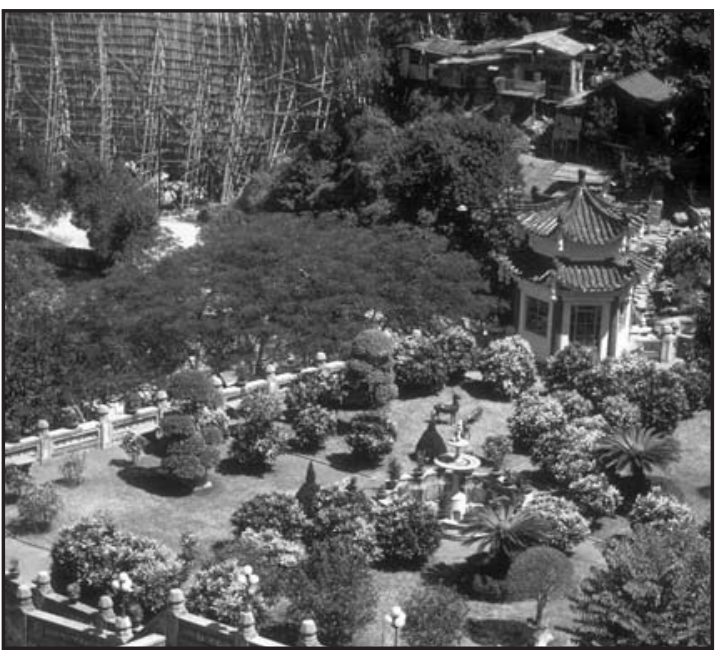

FLORENCE NIGHTINGALE: THE IMPACT OF HER CONTRIBUTIONS IN THE CONTEMPORARY WORLD OF NURSING

\section{SUMMARY}

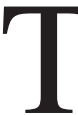

he role of caring is part of human existence and is related to the woman's image that has sought, through this practice, a form of survival that has evolved into broader areas such as promotion and health maintenance.

Objective: To reflect on the contributions of Florence Nightingale for the care exercise in the current days.

Methodology: It is a reflective study with historical perspective, structured by themes, whose sources of data collection were journal articles, books, and critical works approached in the Nursing Academic Master.

Results: Florence Nightingale became the character that retracts the nursing profession through their worldview, becoming a benchmark of life and professional practice in this area of health.

Conclusions: We found that her theoretical vision contributed to the demystification of disparities related to gender, favoring the exercise of the intellectual capacity of women in society. She has received this merit through her scientific knowledge, giving an organized profile to the class. Her care was recommended to the human being and directly associated to his environment, expressions 
of a holistic work, pre-announcing the definition that includes the individual totality in the field of nursing.

Key words: nursing; history; health promotion.

\section{FLORENCE NIGHTINGALE: EL IMPACTO DE SUS CONTRIBUCIONES EN EL MUNDO CONTEMPORÁNEO DE LA ENFERMERÍA}

\section{RESUMEN}

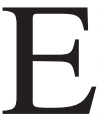
1 papel de la atención es parte de la existencia humana y se relaciona con la imagen de la mujer, que buscó, a través de esta práctica, una forma de supervivencia que se ha desarrollado en ámbitos más amplios, como la promoción y el mantenimiento de la salud.

Objetivo: Reflexionar sobre las contribuciones de Florence Nightingale para el ejercicio del cuidado en la actualidad.

Metodología: Se trata de un estudio reflexivo con perspectiva histórica, estructurada por temas, cuyas fuentes de recolección de datos fueron artículos de periodicos publicados, libros y obras de crítica presentados en la Maestria Académica en Enfermería.

Resultados: Florence Nightingale se convirtió en el personaje que representa a la profesión de enfermería a través de su visión del mundo, convirtiéndose en un punto de referencia de la vida y la práctica profesional en esta área de la salud.

Conclusiones: Se encontró que su visión teórica contribuyó para la desmitificación de las disparidades relacionadas con el género, favoreciendo el ejercicio de la capacidad intelectual de las mujeres en la sociedad. Ella ha recibido esta distinción a través de sus conocimientos científicos, dando un carácter organizado a la clase de la Enfermería. Su atención se recomendó a los seres humanos directamente vinculados a su entorno, las expresiones de una obra integral, pre-anunciando una definición que incluye la totalidad de los individuos en el ámbito de la enfermería.
Palabras claves: enfermería; historia; promoción de la salud.

\section{RESUMO}

$\mathrm{O}$ papel de cuidar faz parte da existência humana e está relacionado à imagem da mulher, que buscava, através dessa práxis, uma forma de sobrevivência que evoluiu para âmbitos mais abrangentes, como a promoção e manutenção da saúde.

Objetivo: Refletir sobre as contribuições de Florence Nightingale para o exercício do cuidado na atualidade.

Metodologia: É um estudo reflexivo com perspectiva histórica, estruturado por temáticas, cujas fontes de obtenção dos dados foram artigos de periódicos publicados, livros, e trabalhos críticos abordados no Mestrado Acadêmico de Enfermagem.

Resultados: Florence Nightingale passou a ser a personagem que retrata a profissão de enfermagem através da sua visão de mundo, tornando-se um referencial de vida e de prática profissional para esta área da saúde.

Conclusões: Constatou-se que a sua visão teórica contribuiu para a desmistificação de disparidades relacionadas ao gênero, favorecendo o exercício da capacidade intelectual da mulher na sociedade. Ela recebeu esse mérito por meio de seu conhecimento científico, conferindo um caráter organizado à categoria. Seu cuidado era preconizado ao ser humano e associado diretamente ao seu meio ambiente, expressões de um trabalho holístico, pré-anunciando a definição que contempla a totalidade do indivíduo no campo da enfermagem.

Descritores: enfermagem; história; promoção da saúde.

\section{INTRODUÇÃO}

A evolução histórica da enfermagem de acordo com Terra et al. (2006), evidencia um percurso de grandes conquistas para a classe. Trata-se de questões associadas, durante o surgimento das pri- 
meiras civilizações no mundo, às causas sobrenaturais e à crença de que as pessoas que possuíam o poder de curar enfermidades eram responsáveis pelo cuidado em saúde. Nesse processo, a religião passou a ser alvo provedor do bem-estar das populações da época, fortalecendo concepções de que a doença era causada por pecados e desprazeres aos deuses. Muitas ações contribuíram, lentamente, para a constituição da profissão de enfermagem, formalizada no período da era cristã, com a presença das mulheres diaconisas.

O amor, o carinho e a preocupação com o bemestar do outro passaram a conduzir um trabalho em saúde mais organizado, aproximando as ações da enfermagem, em meados do século XIX, à liderança e à definição de objetivos em sua prática, fato que oportunizou a ascensão das mulheres na sociedade, dado o exercício do seu trabalho honrado e de impacto social (TERRA et al., 2006). Nessa perspectiva, no século $\mathrm{XX}$, sob forte influência de Florence Nightingale, a enfermagem passou a refletir sobre a sua atuação, idealizando princípios técnicos e educacionais à categoria, que constituíram a enfermagem moderna (OLIVEIRA, PAULA e FREITAS, 2007). Assim, Florence construiu seu legado científico a partir do contato que manteve com os mendigos, andarilhos e aqueles enfermos oriundos das guerras pertinentes à época. Os cuidados de enfermagem passaram então, aos poucos, a valorizar o indivíduo e o adequado ambiente para a prestação dos cuidados em saúde, integrando as práticas de cunho experiencial, lógico e moral, à edificação da profissão de enfermagem (LEOPARDI, 2006).

Assim, transformações econômicas, sociais e políticas ocorridas na sociedade brasileira tornaram-se fatores determinantes para a importação de tecnologias na construção e organização de espaços assistenciais, como os hospitais, considerando para tal, a abordagem dos problemas de saúde, adequando-os gradativamente à sustentação dos novos programas governamentais de saúde, notadamente na saúde pública (BARREIRA, 2005).

Convém destacar que o cuidado enquanto ação social é arte, no momento em que se utiliza os conhecimentos de forma coerente e em prol da qualidade de vida de um indivíduo. Posto isso, torna-se necessário compreender que a palavra "enfermei- ro", no latim, está intimamente conectada ao legado repassado por Florence, pois significa nutrix, ou seja, aquele que nutre, encoraja e protege os que necessitam de atenção para com a sua saúde (TERRA et al., 2006).

A partir dessa constatação, afirma-se que Florence é a precursora da enfermagem, pois elevou o status dessa carreira, qualificando a assistência através de seus ensinamentos históricos e universais. Eles se baseavam no cuidado do outro e na potencialização das forças subjetivas de cada pessoa, tornando-a uma teórica e uma referência científica atual para a ação integral do trabalho em saúde. Contudo, além de Florence, destacam-se as iniciativas da enfermeira Anna Nery, que participou ativamente da Guerra do Paraguai, no século XIX e em 1923, edificou a Escola de Enfermeiras do Departamento Nacional de Saúde, no Brasil. Assim como o trabalho de Wanda de Aguiar Horta, na década de 1970, direcionado ao emprego da sistematização das ações de enfermagem permeado pelo método científico, colaborando para o aperfeiçoamento da classe (KLETEMBERG et al., 2010).

Por conseguinte, objetiva-se, a partir deste estudo, refletir sobre as contribuições de Florence Nightingale para o exercício do cuidado na atualidade.

\section{CAMINHO METODOLÓGICO}

Trata-se de um estudo reflexivo com perspectiva histórica cuja ideia surgiu mediante as aulas instigantes propostas pela Disciplina de Práticas de Atenção, Ensino e Pesquisa em Enfermagem e Saúde desenvolvida no Programa de PósGraduação da Faculdade de Enfermagem da Universidade Federal de Pelotas/UFPel/ RS.

A construção do artigo foi realizada a partir de pesquisa bibliográfica Gil (2007) em periódicos publicados nas fontes de dados da Scielo (Scientific Electronic Library Online), PubMed (Publicações Médicas) e Lilacs (Literatura LatinoAmericana e do Caribe em Ciências da Saúde), no período de 2002 a 2010 através dos descritores "Florence", "Nightingale" e "Enfermagem". Os critérios de seleção foram conter os descritores, estar escrito em língua portuguesa, espanhola ou inglesa e ter resumo disponível. A seleção dos artigos foi realizada a partir da leitura prévia dos resu- 
mos, selecionando aqueles trabalhos que correspondiam ao tema, os quais constam nas referências do presente estudo. Também foram utilizados alguns livros direcionados a proposta do estudo e artigos trabalhados no decorrer da disciplina.

Posteriormente, foi conduzida a análise de conteúdo delineada por Minayo (2007), seguida da ordenação e classificação dos dados em três temáticas incorporadas no decorrer do texto, as quais foram: A construção histórica da enfermagem, Florence Nightingale: determinação em prol da enfermagem e A contemporaneidade do cuidado e o legado de Florence Nightingale.

\section{RESULTADOS E DISCUSSÃO A CONSTRUÇÃO HISTÓRICA DA ENFER- MAGEM}

Os primeiros achados que fazem referência à enfermagem foram encontrados na Bíblia, no Antigo Testamento, instituindo o cuidado como uma prática significativa da enfermagem, a qual busca promover a saúde, o conforto e a prevenção de doenças à população, desde os primórdios de sua existência (NAUDERER e LIMA, 2005).

Nesse processo histórico, o cuidar passou a ser desenvolvido como forma de sobrevivência, a fim de manter a alimentação, a reprodução e a defesa da espécie humana, ações estas vinculadas à imagem da mulher, envolvida nos laços da maternidade, no cuidar dos recém-nascidos, dos idosos e dos enfermos, de modo a garantir a manutenção da vida (ZEFERINO et al., 2008).

Com o surgimento do Cristianismo, a enfermagem foi fortemente influenciada pela supremacia religiosa. O cuidar continuava como uma das funções femininas, sendo, nesse período, realizado pelas mulheres consagradas ou irmãs de caridade, que eram mulheres solteiras (diaconisas), as virgens e as viúvas, que prestavam cuidados sem remuneração, em nível espiritual e protegiam a integridade corporal, por meio de castidade e pureza (ALVES et al., 2005; ZEFERINO et al., 2008). Neste enfoque, o cuidado passou então a evoluir no plano assistencial, detendo-se aos corpos sofredores e atingidos por enfermidades, dissociando assim, o corpo do espírito (ZEFERINO et al., 2008; KLETEMBERG et al., 2010).

Contudo, a falta de controle das doenças e as condições de moradia em conglomerados incenti- varam a Igreja Católica a criar e expandir as instituições de caridade onde era dispensado o cuidado aos doentes (ALVES et al., 2005). Esses estabelecimentos são considerados os primeiros registros do que, na contemporaneidade, viria a ser o hospital. Essas instituições não tinham como finalidade a cura, eram apenas de assistência aos pobres e, de certa forma, serviam como local de separação e exclusão, uma vez que o enfermo era um potencial disseminador de doenças e, como tal, precisava ser isolado (MUSSI, 2005).

O período do Renascimento provocou uma revolta contra a preeminência da Igreja Católica, quando foram dissolvidas ordens religiosas e o trabalho das mulheres consagradas e irmãs de caridade. O advento do Capitalismo e da Revolução Industrial demarcou o início de uma fase de decadência à enfermagem que perdurou do final do século XVII até a metade do século XIX. Sobrevém uma mudança no papel das mulheres na sociedade, onde uma parcela vai trabalhar na indústria e outra se resigna aos seus lares e à obediência aos seus maridos. O cuidado aos doentes, nos hospitais, é então deixado a cargo de mulheres imorais, analfabetas, prostitutas, já que estas não serviam para a indústria, o que se tornara um momento difícil para a ascensão da enfermagem, conhecido como "Anos Negros da Enfermagem" trazido por Nauderer e Lima (2005, p.75), pois a classe continuava a prestar serviços aos pobres, aos doentes, sendo considerado um ofício servil, pouco desejável, em virtude da excessiva carga horária, da baixa remuneração e do estressante trabalho.

As descobertas no campo da física e química, no final do século XIX, vieram apurar os conhecimentos na medicina, auxiliando no diagnóstico e tratamento de doenças (BACKES, 2000). A prática da enfermagem começa então a distanciar-se dos valores morais e religiosos herdados do passado e adota o modelo biomédico, valorizando o tecnicismo (TERRA et al., 2006).

O cuidado, que era prestado como forma de promoção e conservação da vida, fica em segundo plano, e as práticas de enfermagem sintetizam a alocação de técnicas que almejavam apenas o tratamento da doença e a cura. Em contrapartida, a enfermagem começa a distanciar-se de sua origem, e o cuidado passa paulatinamente a restringir-se, havendo um desaparecimento da vinculação entre 


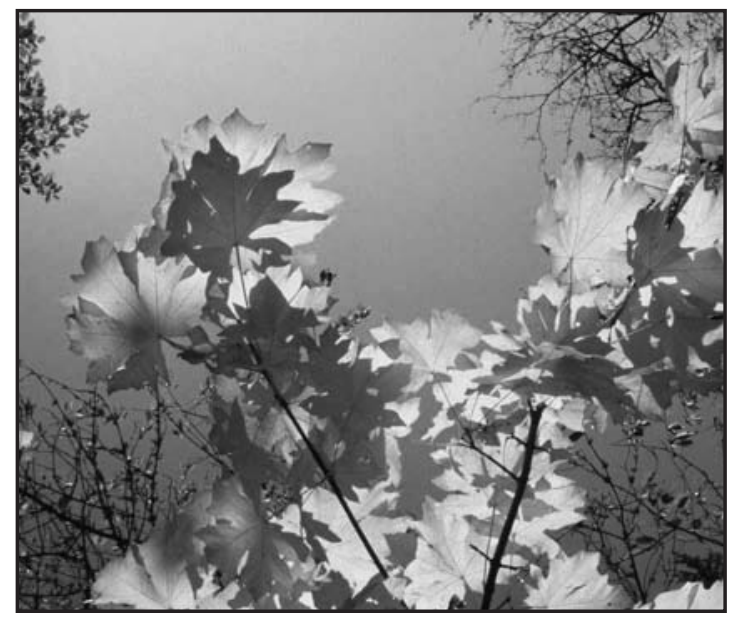

o ser humano e o universo, o ambiente e o grupo social (TERRA et al., 2006). A progressão do capitalismo necessitava do corpo como força de trabalho, o novo hospital surge como uma instituição disciplinadora desse ambiente desordenado, como resposta às demandas de uma nova ordem social (MUSSI, 2005). Atrelado a este processo, surge na Modernidade, com a decadência da hegemonia positivista como concepção científica, o avanço do conhecimento na área da saúde, com conceitos importantes vinculados a ação da enfermagem, como, doença, saúde, ser humano e a própria enfermagem, delineados também por Florence Nightingale em sua caminhada, os quais são utilizados nos dias atuais (KLETEMBERG et al., 2010).

\section{FLORENCE NIGHTINGALE: DETERMINAÇÃO EM PROL DA ENFER- MAGEM}

A enfermagem, ao longo dos tempos, foi sofrendo influências significativas na sua constituição. Uma das personagens que se destacou e permaneceu atuante nesse processo foi Florence Nightingale, mulher determinada, que nasceu na Itália, em Florença, no dia 12 de maio de 1820, tornando-se precursora da enfermagem atual, pois se preocupava com o bem-estar dos indivíduos, especialmente aqueles mais desprovidos de atenção à saúde. Sua capacidade perspicaz se destacava, na época, dada a influência intelectual de sua família, que a estimulava ao pensamento crítico e à educação, como requisitos para a ascensão social (LEOPARDI, 2006).
Florence colaborou para a consolidação de transformações sociais, na segunda metade do século XIX, na Inglaterra, com sua presença em campanhas de promoção à saúde e em conflitos, como a guerra da Criméia em 1854, ações estas que ressaltaram o valor ambientalista de sua teoria, incorporando atitudes sanitaristas, administrativas e epidemiológicas, que evidenciaram seu caráter moderno de operacionalizar as práticas da profissão de enfermagem (LEOPARDI, 2006). Dentre seus objetivos, Florence estava determinada a potencializar as forças restauradoras que existiam no ambiente onde o paciente estava inserido. A manutenção da saúde estava associada ao equilíbrio entre o ser humano e o ambiente que o circundava, tornando o enfermeiro um sujeito que colaborava para promover a relação harmoniosa entre o ser e o estar na sociedade (MACEDO et al., 2008).

$\mathrm{Na}$ época, Florence já se preocupava com as dimensões físicas, psicológicas e sociais do ser humano, conferindo uma atenção humanitária e holística, tão emergente nos dias atuais, assim como atentava para o autocuidado, que era incentivado pelas enfermeiras, sob um enfoque educativo no processo de cuidar de si (LEOPARDI, 2006; MACEDO et al., 2008).

Convém destacar que, sob influência do caráter ambientalista, Florence detinha-se aos elementos físicos, como forma de obtenção de cura para doenças e restauração das forças e energias do paciente; dentre estes, a ventilação, a iluminação, a limpeza do ambiente, o controle de calor, do odor, dos ruídos e a alimentação eram especialmente analisados, conferindo perspectivas preventivas e curativas no cuidar em saúde (MACEDO et al., 2008).

Nesse plano de ideias, expõe-se ainda o caminho imperativo de Florence, no que tange à história intelectual da enfermagem. Em meados de 1859, ela escreveu o seu primeiro livro, denominado Notas Sobre Enfermagem, seguido de várias outras publicações, que expuseram suas percepções acerca da saúde/doença e o ambiente. Em 1860, Florence auxiliou na construção da Escola de Enfermagem Nightingale, no Hospital Saint Thomas, na Inglaterra, o que passou a valorizar a categoria como profissão e concorreu para reconhecê-la mundialmente (LEOPARDI, 2006). 
Desse modo, a constituição da enfermagem foi sendo aprimorada, edificando saberes com essência no cuidado, como práxis em saúde; distinguindo, a cada dia, o trabalho da enfermeira das demais profissões existentes. E esta evolução social da enfermagem direcionou a organização das ações centradas na atenção ao indivíduo, na sua relação com o meio, bem como na adesão de instrumentos que conferem maior responsabilidade e autonomia à profissão (TAYLOR, LILLIS e LEMONE, 2007).

\section{A CONTEMPORANEIDADE DO CUIDADO E O LEGADO DE FLORENCE NIGHTINGALE}

$\mathrm{O}$ cuidado visa à construção e à conservação da identidade humana. Ele não se resume simplesmente a uma manifestação, mas é um conjunto harmônico e interdependente, é uma expressão significativa da essência humana, que contempla a pessoa em sua unidade e totalidade bio/psico/sócio/espiritual. Por essa razão, as pessoas, desde seu nascimento, necessitam do cuidado para crescer, desenvolver-se, viver e morrer dignamente. Dessa forma, a enfermagem sempre se destacou, e fundamentou os seus princípios, assim como as suas crenças e valores, de forma empírica, porém a evolução da ciência fez com que o enfermeiro refletisse acerca disso e questionasse sua prática, desenvolvendo um corpo de conhecimentos específico, passando a guiar suas ações cuidativas nos processos de formação dos profissionais, na pesquisa e no exercício da profissão (SOUZA, 2001). Florence Nightingale, em sua época, já valorizava o conhecimento científico, bem como conceitos acerca do meio ambiente, ventilação e condições sanitárias, ressaltando a comunicação verbal e não verbal como valiosos instrumentos de cuidado (STAMM, 2002).

Entretanto, se olharmos o cuidado do ponto de vista do usuário do sistema de saúde, podemos constatar que este não reclama da falta de conhecimento tecnológico no seu atendimento, mas sim da falta de interesse e compromisso em torno de si e do seu problema (MERHY, 1998). O trabalho em saúde acaba perdendo seu significado de ajuda e restauração do bem-estar, para tornar-se apenas uma prestação de serviço mecânica e massificada, esvaziada de valores humanos. Isto porque o profissional de saúde não empenha paixão naquilo que faz, pois o tempo para o prazer de escutar um paciente é substituído pelo aumento do número de pessoas atendidas, acarretando o prejuízo da qualidade comprometida no seu trabalho (OLINISKI e LACERDA, 2004).

Que tipo de crise tecnológica e assistencial é esta? Ao olharmos com atenção os processos de trabalho, no conjunto das intervenções assistenciais, identificamos que qualquer abordagem de um profissional de saúde junto a um paciente produz-se através de um trabalho vivo em ato, no encontro entre duas pessoas, no diálogo, sendo criada uma responsabilização em torno do problema que vai ser enfrentado. Pois os pacientes buscam nos trabalhadores de saúde o acolhimento, responsabilização e vínculo (MERHY, 1998).

Podemos retroceder na história e, traçando um paralelo entre a era pós-Nightingale e o momento recente, o cuidado deixa de ter seu valor central e a ênfase está no saber tecnicista, qual seja: o diagnóstico (STAMM, 2002). A lógica capitalista privilegia esse padrão, estimulando as pessoas a produzirem cada vez mais, consagrando a maior parte do seu tempo ao trabalho, à produtividade, à competitividade, não favorecendo sentimentos de realização e prazer no trabalho (OLINISKI e LACERDA, 2004).

Após essa fase tecnicista, recentemente se faz um resgate da essência da enfermagem, em que o paciente passa a ser ouvido e respeitado no seu todo. Um paradigma emergente na realidade brasileira, que tem como base filosófica o cuidado ao ser humano e sua inter-relação com o meio ambiente, no contexto das próprias experiências de vida, com foco na morte/renascimento, processos de ser e viver de forma mais saudável possível que estão presentes na construção do cuidado transdimensional (STAMM, 2002).

Dentro da prestação de serviços em saúde, no que diz respeito à enfermagem, o que produzimos não se pode quantificar, é um ato que se desfaz na mesma hora em que é ofertado. Podemos medi-lo de acordo com a satisfação de quem o recebe. Porém o conceito de caridade e benevolência repassado a esse tipo de serviço, e que lhe conferia uma conotação de doação, vem tomando novos rumos (MERHY, 1998).

Outrossim, o cuidado deve ser compreendido como produto e serviço nas suas múltiplas 
dimensões, relações e interações, ou seja, como um sistema de produção de serviços personificado e singular, na sua maneira de ser e existir na sociedade. $\mathrm{O}$ que exige um posicionamento diferenciado por parte do enfermeiro que, ao interagir e dialogar no seu campo de atuação, experimenta evidências da complexidade do cuidado: seja nas variadas expressões sociais, profissionais, familiares e individuais (BACKES et al., 2006).

Em 2010, se completam 100 anos da morte de Florence Nightingale, uma mulher que viveu à frente de seu tempo, atuando tanto no contexto hospitalar, quanto no político, social e ecológico. Seus pressupostos se mantêm atuais e norteiam enfermeiros por todo o mundo. Com ela, a enfermagem iniciou sua caminhada científica, conferindo caráter organizado à categoria, viabilizando a construção da Sistematização da Assistência de Enfermagem (SAE), além de preconizar o cuidado ao ser humano e sua relação com o meio ambiente, como focos da enfermagem. Expressões de um trabalho holístico, de certo modo, pré-anunciando a definição que atualmente contempla a totalidade do indivíduo, o Cuidado Transdisciplinar.

\section{CONSIDERAÇÕES FINAIS}

Ao refletirmos sobre o impacto desencadeado pelo cuidado no seu processo evolutivo, percebemos que o mesmo sofreu mudanças na sua conotação, sendo desenvolvido nos primórdios, de geração a geração, de modo empírico e como forma de doação. Florence Nightingale, por sua vez, incorporou valores essenciais para a promoção da saúde, sob um olhar holístico, resgatando o cuidado como uma ciência. Finalmente, temos no cuidado muito mais que uma ação benevolente. Ele é uma ferramenta de trabalho que confere autonomia ao enfermeiro e o difere como profissional de saúde, no momento em que percebe o ser na sua heterogeneidade.

Nessa perspectiva, Florence Nightingale, com sua teoria ambientalista, focou o sujeito na sua integralidade, preocupando-se com o ambiente que o circundava, além de valorizar hábitos de higiene, registrando, assim, as primeiras notas epidemiológicas de enfermagem. Ela reorganizou as ações da profissão, de modo a elaborar a sua sistematização, abordando conceitos, tais como ambiente, iluminação, aeração e alimentação, pressupostos signifi-

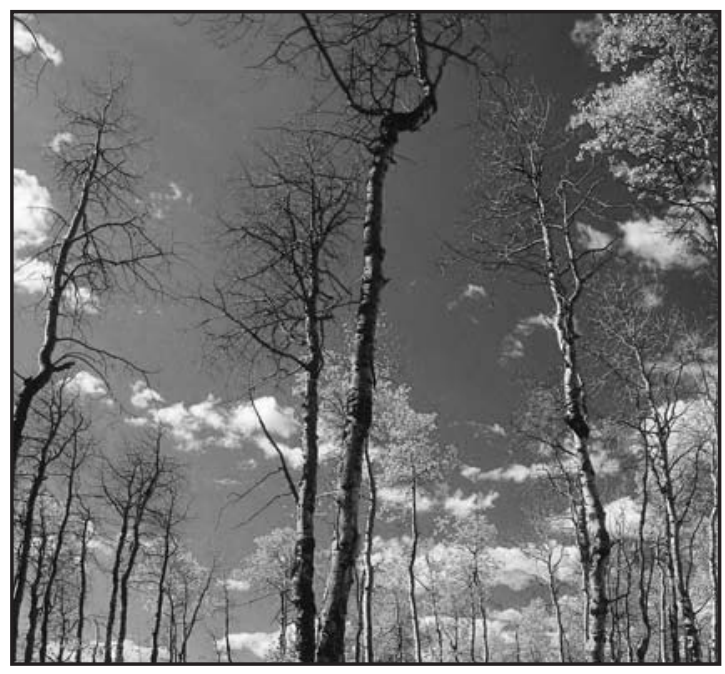

cativos para a história da enfermagem. Contribuiu, assim, para a formação do conceito global que contempla o ser humano como um ser bio/psico/social/espiritual.

Portanto, o enfermeiro contemporâneo pode fazer uma releitura do que é o cuidar, fundamentálo no antigo e no novo contexto, alavancando o empreendedorismo da profissão, com vistas a conquistar e explorar os espaços intercessores para promover a mudança de paradigmas na enfermagem.

\section{REFERÊNCIAS}

- ALVES, M.D.S.; ORIÁ, M.O.B.; FRANCO, E.S.; COSTA, M.S.; BARROSO, M.G.T. (2005) História da enfermagem registrada nas artes plásticas: do século XVI ao século XX. Texto Contexto Enferm. Florianópolis, out/dez 14(4): 513-9. - BACKES, V.M.S. (2000) Estilos de pensamento e práxis na enfermagem: a contribuição do estágio pré-profissional. Ijuí: Unijuí, p.79.

BACKES, D.S.; SOUSA, F.G.M.; MELLO, A.L.S.F.; ERDMANN, A.L.; NASCIMENTO, K.C.; LESSMANN, J.C. (2006) Concepções de cuidado: uma análise das teses apresentadas para um programa de pós-graduação em enfermagem. Texto Contexto Enferm, Florianópolis 15(n. esp): 71-8. BARREIRA, I.A. (2005) A reconfiguração da prática da enfermagem brasileira em meados do século 20. Texto contexto - enferm., Florianópolis, dez. 14(4): 480-87.

GIL, A.C. (2007) Métodos e técnicas de pesquisa social. 5.ed. São Paulo: Atlas.

- KLETEMBERG, D.F.; SIQUEIRA, M.T.D; MANTOVANI, M.F.; PADILHA, M.I.; AMANTE, L.N.; ANDERS, J.C. (2010) O processo de enfermagem e a lei do exercício profissional. Rev. bras. enferm., Brasília, fev. 63(1): 26-32.

- LEOPARDI, M.T. (2006) Teoria e método em assistência de enfermagem. $2^{\mathrm{a}}$ ed. Rev Ampl. Florianópolis: Soldasft; p.369. - MACEDO, P.O.; QUITETE, J.B.; LIMA, E.C.; SANTOS, I.; 
VARGENS, O.M.C. (2008) As tecnologias de cuidado de enfermagem obstétrica fundamentadas pela teoria ambientalista de Florence Nightingale. Esc. Anna Nery Rev. Enferm. [periódico na Internet]. [acesso em 2009 Jun 15];12(2): 341-7. Disponível

em: http://www.eean.ufrj.br/revista_enf/20082/24ARTIGO20.pdf. - MERHY, E.E. A (1998) perda da dimensão cuidadora na produção da saúde: uma discussão do modelo assistencial e da intervenção no seu modo de trabalhar a assistência. In: Campos CR, Malta DC, Reis AT, Santos AF, Merhy EE. (Org.). Sistema Único de Saúde em Belo Horizonte: reescrevendo o público. São Paulo: Xamã; p. 121-42.

- MINAYO, Maria Cecília de Souza. (2007) O desafio do conhecimento: pesquisa qualitativa em saúde. 10.ed. São Paulo: Hucitec.

- MUSSI, F.C. (2005) Conforto e lógica hospitalar: análise a partir da evolução histórica do conceito conforto na enfermagem. Acta Paul Enferm 18(1): 72-81.

- NAUDERER, T.M.; LIMA, M.A.D.S. (2005) Imagem da enfermeira: revisão da literatura. Rev Bras Enferm. jan/fev 58(1): 74-7.

- OLINISKI, S.R.; LACERDA, M.R. (2004) As diferentes faces do ambiente de trabalho em saúde. Cogitare Enferm, Curitiba, jul/dez 9(2): 43-52.
- OLIVEIRA, M.L.; PAULA, T.R.; FREITAS, J.B. (2007) Evolução histórica da assistência de enfermagem. ConScientiae Saúde, São Paulo 6(1): 127-136.

- SOUZA, M.F. (2001) As teorias de enfermagem e sua influência nos processos cuidativos. In: Gualda DMR, Melleiro MM, Anabuki MM. (Org.). Sistema de enfermagem: evolução e tendência. São Paulo: Ícone; p.29-39.

- STAMM, M. (2002) Evolução do cuidado na enfermagem até o cuidado transdimensional: uma revisão de literatura. Ciência cuidado e saúde, Maringá. jul/dez 1(2): 293-8.

- TAYLOR, C.; LILLIS, C.; LEMONE, P. (2007) Fundamentos de enfermagem: a arte e a ciência do cuidado de enfermagem. $5^{\mathrm{a}}$ ed. Porto Alegre: Artmed;. p.1592.

- TERRA, M.G.; CAMPONOGARA, S.; SILVA, L.C.; GIRONDI, J.B.R.; NASCIMENTO, K.; RADÜNZ, V. (2006) O significado de cuidar no contexto do pensando complexo: novas possibilidades para enfermagem. Texto Contexto Enferm. Florianópolis. 15 (Esp): 164-9.

- ZEFERINO, M.T.; SANTOS, V.E.P.; WALL, M.I.; ROCHA, P.K.; BLOIS, J.M.; MEIRELES, B.H.S. (2008) Concepções do cuidado na visão de doutorandas de enfermagem. Rev Enferm. UERJ, Rio de Janeiro. jul/set 16(3): 345-350.

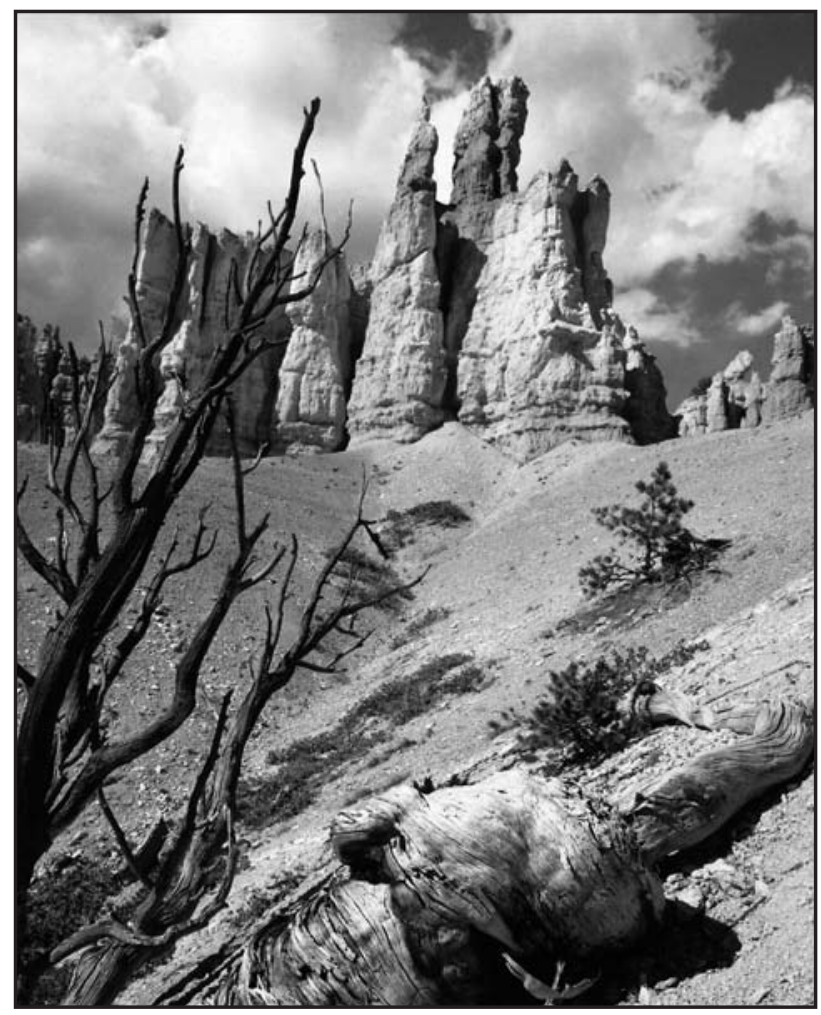

